\title{
Unusual Fries rearrangement of 7-acyloxyquinolin-2-ones- A new way to linear and angular furoquinolin-2-ones
}

\author{
Valery F. Traven, Natalja Ya. Podhaluzina, Andrei V. Vasilyev, \\ and Alexander V. Manaev \\ Department of Organic Chemistry, D. Mendeleev University of Chemical Technology of Russia \\ Miusskaja sq.9, Moscow, 125047, Russia, Phone: 095-978-94-07. Fax: 095-200-42-04 \\ E-mail:traven@main-gw.muctr.edu.ru
}

(received 20 Apr 00; accepted 26 Nov 00; published on the web 04 Dec 00)

\begin{abstract}
Unusual temperature dependence of the Fries rearrangement of 7-acetoxy-4-methylquinolin-2one has been established. The predominant content of 6-acetyl-7-hydroxy-4-methylquinolin-2one in the final reaction mixture at higher temperature $\left(155^{\circ} \mathrm{C}\right)$ is due to a higher thermodynamic stability of this isomer in comparison to 8-acetyl-7-hydroxy-4-methylquinolin-2-one. The preferable formation of 8 -acetyl-isomer at lower temperature $\left(85^{\circ} \mathrm{C}\right)$ seems to be due to the kinetically controlled reaction. By the AM1 calculations, the highest negative charge (by absolute value) at the position 8 has been found both in 7-hydroxy-4-methylquinolin-2-one and in its $\mathrm{AlCl}_{3}$-complex. Both 6- and 8-acetyl-7-hydroxy-4-methylquinolin-2-ones were smoothly transformed to the corresponding linear furo[3,2-g]quinolin-7-one and angular furo[2,3h]quinolin-2-one.
\end{abstract}

Keywords: Fries rearrangement, acyloxyquinolin-2-ones, kinetic control

\section{Introduction}

The Fries rearrangement of acyloxyarenes and acyloxyheteroarenes is a convenient way of corresponding o-hydroxyketones preparation. It goes smoothly also with acyloxycoumarins. We have previously found this reaction to be extremely useful in the syntheses of both linear and angular furocoumarins [1-3], well known as photochemotherapeutic medicines [4-6].

Quinolin-2-ones are nitrogen-containing analogs of coumarins. However, there are no in literature any data, concerned the Fries rearrangement of acyloxyquinolin-2-ones. Meanwhile, 
the resulted o-(hydroxy)acyl-derivatives seem to become rather useful in the furoquinolin-2-ones preparation, which show also a significant photobiochemical activity [7].

We have carried out the Fries rearrangement of 7-acetoxy-4-methylquinolin-2-one at different temperature and compared the results with those of the 7-acetoxy-4-methylcoumarin rearrangement.

\section{Results and Discussion}

7-Hydroxy-4-methylquinolin-2-one (1) has been prepared by heating of m-aminophenol and acetoacetic ester at $140-150{ }^{\circ} \mathrm{C}$ [8]. This compound was then acetylated. Accordingly to the Fries rearrangement procedure, the resulted 7-acetoxy-4-methylquinolin-2-one (2) has been treated by excess of $\mathrm{AlCl}_{3}$ at different temperatures from $85{ }^{\circ} \mathrm{C}$ to $155{ }^{\circ} \mathrm{C}$. The composition of the rearrangement products has been analyzed by the $1 \mathrm{H}$ NMR spectra. In general, two isomers: 8acetyl-4-methylquinolin-2-one (3) and 6-acetyl-4-methylquinolin-2-one (4) - have been detected in the reaction mixtures (scheme 1).

The compositions of the final reaction mixtures and analytical chemical shifts for the compounds 1-4 are listed in the Table 1.<smiles>Cc1cc(=O)[nH]c2cc(OC(C)C)ccc12</smiles>

2<smiles>CC(=O)c1c(O)ccc2c(C)cc(=O)[nH]c12</smiles>

3<smiles>CC(=O)c1cc2c(C)cc(=O)[nH]c2cc1O</smiles>

4<smiles>Cc1cc(=O)[nH]c2cc(O)ccc12</smiles>

\section{Scheme 1}


The compound $\mathbf{3}$ predominates in the reaction mixture when the rearrangement was carried out at $85^{\circ} \mathrm{C}$. Only traces of the compound 4 were detected in these conditions. Increase of the reaction temperature to $125^{\circ} \mathrm{C}$ and then to $155^{\circ} \mathrm{C}$ leads to a sharp decrease of the compound 3 content. On opposite, compound $\mathbf{4}$ becomes to be predominant one. The yield of this compound goes up to $94 \%$ when the rearrangement temperature is equal to $155^{\circ} \mathrm{C}$.

Table 1. Temperature dependence of product composition of Fries rearrangement (contents of compounds $1-4$ are given in $\%$ by $1 \mathrm{H}$ NMR data)

Compound number (analytical chemical shift in ppm) $\quad 85^{\circ} \mathrm{C} \quad 125-130^{\circ} \mathrm{C} \quad 150-155^{\circ} \mathrm{C}$

\begin{tabular}{llccc}
\hline $\mathbf{1}(6.12,7.50)$ & 23 & 32 & 1 \\
$\mathbf{2}(6.36,7.73)$ & 26 & 10 & 0 \\
$\mathbf{3}(6.24,7.78)$ & 51 & 18 & 5 \\
$\mathbf{4}(6.24,8.15)$ & 0 & 40 & 94 \\
\hline
\end{tabular}

These results are quite different from those of the 7-acetoxy-4-methylcoumarin (5) Fries rearrangement (scheme 2) [3].<smiles>Cc1cc(=O)oc2cc(OC(C)C)ccc12</smiles>

5<smiles>CC(=O)c1c(O)ccc2c(C)cc(=O)oc12</smiles>

6<smiles>CC(=O)c1cc2c(C)cc(=O)oc2cc1O</smiles>

7

\section{Scheme 2}

8-Acetyl-7-hydroxy-4-methylcoumarin (6) is a predominant product of the reaction at any temperature from $85^{\circ} \mathrm{C}$ to $155^{\circ} \mathrm{C}$, even though the content of the 6-acetyl-isomer (7) increases definitely at higher temperature. A ratio of isomer 6: isomer 7 is equal to 200:1 at temperature $85^{\circ} \mathrm{C}$ and equal to $2.5: 1$ at temperature $155^{\circ} \mathrm{C}$. 
The significant temperature dependence of the Fries rearrangement results of 7acetyloxyquinolin-2-one 2 can be explained regarding the AM1 calculation data. We have found the difference in thermodynamic stabilities of isomers 3 and $\mathbf{4}$ to be rather large one (see the Table 2). The predominance of the isomer 4 at $155^{\circ} \mathrm{C}$ seems to be due to its higher stability: it is more than $8 \mathrm{kcal} / \mathrm{mol}$ more stable than the isomer 3 .

Table 2. Heats of formation $\mathrm{H}_{\mathrm{f}}{ }^{\mathrm{o}}$ of the compounds 3 and 4, 6 and 7

\begin{tabular}{ccccc}
\hline Compound & $\mathbf{3}$ & $\mathbf{4}$ & $\mathbf{6}$ & $\mathbf{7}$ \\
\hline $\begin{array}{c}\Delta \mathrm{H}_{\mathrm{f}}^{\circ}(\mathrm{AM} 1), \\
\mathrm{kcal} / \mathrm{mol}\end{array}$ & -79.29 & -87.56 & -119.27 & -120.38 \\
\hline
\end{tabular}

The preferable formation of the 8-acetyl-isomer 3 at lower temperature $\left(85^{\circ} \mathrm{C}\right)$ seems to be due to the kinetically controlled Fries rearrangement of the compound 2 . We have earlier found the Fries rearrangement to be an intermolecular reaction in the acylhydroxycoumarin series [3]. The same might be quite true for their acyloxyquinolin-2-one analogs. Therefore, the ratelimiting step of the compound 2 Fries rearrangement seems to be an electrophilic attack of acetyl cation on the compound 1 or its $\mathrm{AlCl}_{3}$-complex, since the reaction goes in the large excess of $\mathrm{AlCl}_{3}$. The highest negative charge (by absolute value) at the free positions of the substrate benzene ring will facilitate the rate of the reaction. The diagrams of the AM1 charges in the compound $\mathbf{1}$ and its $\mathrm{AlCl}_{3}$-complex $\mathbf{8}$ are shown below.

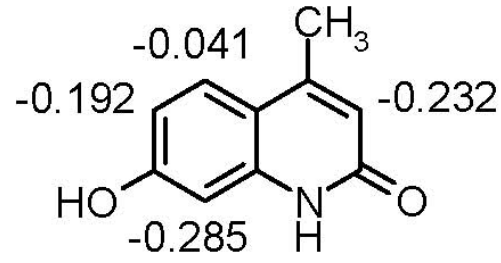

1

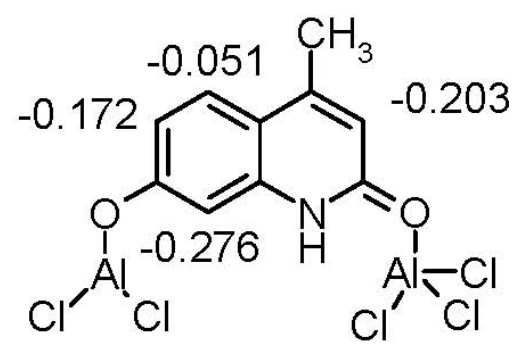

8

The position 8 is much more negatively charged in both structures and looks the more preferable one for the electrophilic attack when compared with the position 6 .

Discussing the results of the compound 5 Fries rearrangement, the following AM1 calculation data should be kept in mind:

thermodynamic stabilities of the isomers $\mathbf{6}$ and 7 are almost equal (Table 2);

the highest negative charge (by absolute value) at the position 8 has been found by the AM1 
calculations of both 7-hydroxy-4-methylcoumarin (9) and its $\mathrm{AlCl}_{3}$-complex (10); it can be seen on the diagrams shown below.

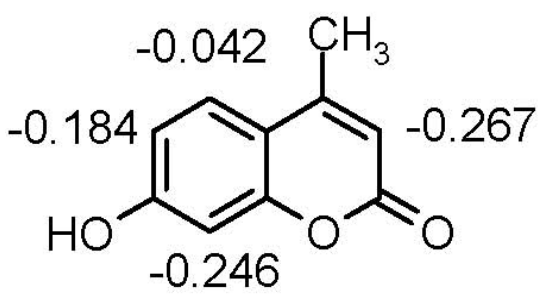

9

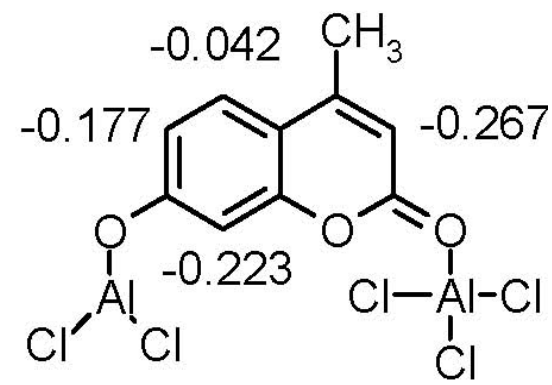

10

As it was expected, acetylquinolin-2-ones $\mathbf{3}$ and $\mathbf{4}$ react easily with phenacylbromides. The corresponding both angular and linear furoquinolin-2-ones (11) and (12) have been isolated with a good yield.<smiles>Cc1cc(=O)[nH]c2c1ccc1oc(C(=O)c3ccc(Cl)cc3)c(C)c12</smiles>

11<smiles>Cc1cc(=O)[nH]c2cc3oc(C(=O)c4ccc(Cl)cc4)c(C)c3cc12</smiles>

12

\section{Experimental Section}

\section{${ }^{1} H$ NMR and Mass Spectra}

${ }^{1} \mathrm{H}$ NMR spectra were recorded on a WP 200 (Bruker) spectrometer at $200 \mathrm{MHz}$ in DMSO-d solutions using TMS as an internal standard. Chemical shifts are given in ppm.

Mass spectra were scanned on a SSQ-710 (Finnigan MAT) spectrometer at the energy of ionizing electrons equal to $70 \mathrm{ev}$. 
7-Hydroxy-4-methylquinolin-2-one (1). m-Aminophenol (1g, $9.16 \mathrm{mmol}$ ) has been heated with ethyl acetoacetate $(1.43 \mathrm{~g}, 11 \mathrm{mmol})$ at temperature $140-150{ }^{\circ} \mathrm{C}$ for about $5 \mathrm{hrs}$. The formed solid was washed by water and recrystallized from ethanol.

Compound 1, white powder (from $\mathrm{EtOH}$ ), yield=25\%, mp 306-307 ${ }^{\circ} \mathrm{C}$ (decomp.) (lit.(8) $330{ }^{\circ} \mathrm{C}$ ).

7-Acetoxy-4-methylquinolin-2-one (2). Compound 1 (1g, $4.6 \mathrm{mmol})$ has been boiled in the excess of acetic anhydride until its dissolution and then for $1.5 \mathrm{hr}$. The resulted solution was cooled and poured into cold water. The precipitate was filtered off and washed by water.

Compound 2, white crystals (from EtOH), yield $=88 \%, \mathrm{mp} 257-258^{\circ} \mathrm{C} .{ }^{1} \mathrm{H}$ NMR $\left(\mathrm{DMSO}-\mathrm{d}_{6}, \delta\right.$, ppm; J, Hz): 2.30(s, 3H, CH3CO-), 2.41(d, 3H, 4-CH3, J $\left.\mathrm{CH}_{3,3}=0.82\right) ; 6.36(\mathrm{q}, 1 \mathrm{H}, \mathrm{H}-3$, $\left.\mathrm{J}_{3, \mathrm{CH} 3}=0.82\right) ; 6.96\left(\mathrm{dd}, 1 \mathrm{H}, \mathrm{H}-6, \mathrm{~J}_{6,5}=8.6, \mathrm{~J}_{6,8}=2.2\right) ; 7.04\left(\mathrm{~d}, 1 \mathrm{H}, \mathrm{H}-8, \mathrm{~J}_{8,6}=2.2\right) ; 7.72(\mathrm{~d}, 1 \mathrm{H}, \mathrm{H}-5$, $\left.\mathrm{J}_{5,6}=8.6\right) ; 11.57(\mathrm{~s}, 1 \mathrm{H}, \mathrm{NH})$. MS (m/z, \%): $217\left(\mathrm{M}^{+}, 57\right)$.

Anal. calc. for $\mathrm{C}_{12} \mathrm{H}_{11} \mathrm{NO}_{3}$ : C 66.35; H 5.10; N 6.45. Found: C 66.45; H 5.08; N 6.46.

6-Acetyl-7-hydroxy-4-methylquinolin-2-one (4). Compound 2 (1g, 4.6 mmol) was mixed with $\mathrm{AlCl}_{3}$ powder $(2 \mathrm{~g}, 15.2 \mathrm{mmol})$ and mixture has been heated at $145-155^{\circ} \mathrm{C}$ during 4 hours. After that the mixture was dilute by water and kept over night. The precipitate that formed was boiled in ethanol during 0.5 hours and filtered off.

Compound 4, white powder, yield $=65 \%, \mathrm{mp} 191-194{ }^{\circ} \mathrm{C}($ decomp. $){ }^{1} \mathrm{H}$ NMR (DMSO-d $6, \delta$, ppm; J, Hz): 2.44(d, 3H, 4-CH3, J $\left.\mathrm{CH}_{3,3}=0.8\right) ; 2.69(\mathrm{~s}, 3 \mathrm{H}, \mathrm{CH} 3 \mathrm{CO}) ; 6.24\left(\mathrm{q}, 1 \mathrm{H}, \mathrm{H}-3, \mathrm{~J}_{3, \mathrm{CH} 3}=0.8\right.$ ); 6.71(s, 1H, H-8); 8.15(s, 1H, H-5); 11.67(s, 1H, OH); 12.21(s, 1H, NH). MS (m/z, \%): $217\left(\mathrm{M}^{+}\right.$, $63)$.

Anal. calc. for $\mathrm{C}_{12} \mathrm{H}_{11} \mathrm{NO}_{3}$ : C 66.35; H 5.10; N 6.45. Found: C 66.18; H 5.11; N 6.40.

8-Acetyl-7-hydroxy-4-methylquinolin-2-one (3). Compound 2 (1g, $4.6 \mathrm{mmol}$ ) was mixed with $\mathrm{AlCl}_{3}$ powder $(2 \mathrm{~g}, 15.2 \mathrm{mmol})$ and mixture has been heated at $80-85{ }^{\circ} \mathrm{C}$ during 4 hours. After that the mixture was dilute by water and kept over night. Compound $\mathbf{3}$ was isolated from the mixture by column chromatography (silica gel, eluent- ethyl acetate). Other compounds from the mixture have not been isolated.

Compound 3, white powder, yield $=15 \%, \mathrm{mp} 259-262{ }^{\circ} \mathrm{C} .{ }^{1} \mathrm{H}$ NMR (DMSO-d $\left.6, \delta, \mathrm{ppm} ; \mathrm{J}, \mathrm{Hz}\right)$ : 2.35(d, 3H, 4-CH3, $\left.\mathrm{J}_{\mathrm{CH} 3,3}=1.2\right)$; 2.65(s, 3H, CH3CO); 6.24(q, 1H, H-3, J $\left.\mathrm{J}_{3, \mathrm{CH} 3}=1.2\right)$; 6.84(d, 1H, H$\left.6, \mathrm{~J}_{6,5}=8.0\right) ; 7.78\left(\mathrm{~d}, 1 \mathrm{H}, \mathrm{H}-5, \mathrm{~J}_{5,6}=8.0\right) ; 12.10(\mathrm{~s}, 1 \mathrm{H}, \mathrm{OH}) ; 12.21(\mathrm{~s}, 1 \mathrm{H}, \mathrm{NH})$.

MS (m/z, \%): 217( $\left.\mathrm{M}^{+}, 61\right)$. Anal. calc. for $\mathrm{C}_{12} \mathrm{H}_{11} \mathrm{NO}_{3}$ : C 66.35; H 5.10; N 6.45. Found: C 66.15; H 5.06; N 6.42. 
8-(4'-Chlorobenzoyl)-4, 9-dimethylfuro[2, 3-h]quinolin-2(1H)-one (11). Compound 3 (1g, $2.84 \mathrm{mmol}$ ) was dissolved in minimal amount of DMSO, added p-chloro phenacylbromide $(0.66 \mathrm{~g}, 2.84 \mathrm{mmol})$ and $\mathrm{K}_{2} \mathrm{CO}_{3}(1 \mathrm{~g})$. The mixture was stirred during 6-8 hours. Then reaction mixture poured into water, precipitate was filtered off. The product was recrystalisation from the acetic acid.

Compound 11, yellow crystals (from $\mathrm{AcOH}$ ), yield $=72 \%$, mp $283-286^{\circ} \mathrm{C}\left(\right.$ decomp.). ${ }^{1} \mathrm{H}$ NMR $\left(\mathrm{DMSO}_{6}, \delta\right.$, ppm; J, Hz): 2.55(d, 3H, 4- $\left.\mathrm{CH}_{3}, \mathrm{~J}_{\mathrm{CH} 3,3}=1.0\right) ; 3.02\left(\mathrm{~s}, 3 \mathrm{H}, 9-\mathrm{CH}_{3}\right) ; 6.99(\mathrm{q}, 1 \mathrm{H}, \mathrm{H}-3$, $\left.\mathrm{J}_{3, \mathrm{CH} 3}=1.0\right) ; 7.38\left(\mathrm{~d}, 2 \mathrm{H}, \mathrm{H}-2^{\prime}, \mathrm{J}_{2}{ }^{,}, 3^{\prime}=9.0\right) ; 7.51\left(\mathrm{~d}, 2 \mathrm{H}, \mathrm{H}-5, \mathrm{~J}_{5,6}=8.7\right) ; 7.78\left(\mathrm{~d}, 2 \mathrm{H}, \mathrm{H}-3^{\prime}, \mathrm{J}_{3^{\prime},{ }^{\prime}}=9.0\right)$; 8.03(d, $\left.2 \mathrm{H}, 6-\mathrm{H}, \mathrm{J}_{6,5}=8.7\right)$. MS (m/z, \%): 351( $\left.\mathrm{M}^{+}, 100\right)$. Anal. calcd. for $\mathrm{C}_{20} \mathrm{H}_{14} \mathrm{ClNO}_{3}$ : $\mathrm{C}$ 68.29; H 4.01; N 3.98; Cl 10.08. Found: C 68.03; H 3.95; N 3.71; Cl 10.21.

2-(4'-Chlorobenzoyl)-3, 5-dimethylfuro[3, 2-g]quinolin-7(8H)-one (12). This compound has been prepared as the compound $\mathbf{1 1}$ given above.

Compound 12, green-yellow crystals (from AcOH), yield $=84 \%$, mp 309-312 ${ }^{\circ} \mathrm{C}\left(\right.$ decomp.). ${ }^{1} \mathrm{H}$ NMR (DMSO-d 6 , $\delta, p p m ; J, H z): 2.62\left(\mathrm{~s}, 3 \mathrm{H}, 5-\mathrm{CH}_{3}\right) ; 2.71\left(\mathrm{~s}, 3 \mathrm{H}, 3-\mathrm{CH}_{3}\right) ; 6.58(\mathrm{~s}, 1 \mathrm{H}, \mathrm{H}-6)$;

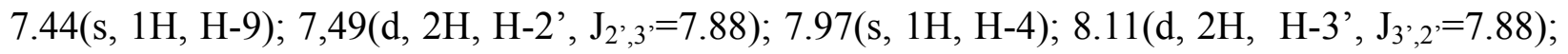
$11.07(\mathrm{~s}, 1 \mathrm{H}, \mathrm{NH})$.

$\operatorname{MS}(\mathrm{m} / \mathrm{z}, \%): 351\left(\mathrm{M}^{+}, 100\right)$.

Anal. calcd. for $\mathrm{C}_{20} \mathrm{H}_{14} \mathrm{ClNO}_{3}$ : C 68.29; $\mathrm{H}$ 4.01; N 3.98; $\mathrm{Cl}$ 10.08. Found: $\mathrm{C} 68.13 ; \mathrm{H} \mathrm{3.99;} \mathrm{N}$ 3.62; $\mathrm{Cl} 10.09$.

\section{References}

1. Traven, V. F.; Kravtchenko, D. V.; Chibisova, T. A. Mendeleev Commun. 1995, 21.

2. Traven, V. F.; Kravtchenko, D. V.; Chibisova, T. A.; Shorshnev, S. V.; Eliason, R.; Wakefield, D. H. Heterocyclic Commun., 1996, 2, 345.

3. Kravtchenko, D. V.; Chibisova, T. A.; Traven, V. F. Zhurnal Organicheskoi Khimii, 1999, 35, 924.

4. Murray, R. D. H. The Natural Coumarins, occurrence, chemistry and biochemistry. WileyInterscience: New York, 1982.

5. Fahr, E. Pharmazeutishe Zeitung 1982, 127, 163.

6. Edelson, R. L. J. Photochem. Photobiol., B: Biol. 1991, 10, 165.

7. Guiotto, A.; Chilin, A.; Manzini, P.; Dall'Aqua, F.; Bordin, F.; Rodighiero, P. IL Farmaco, 1995, 50, 479 . 
8. Limaye, D. B. Ber., 1932, Bd 65., №1, s. 375-377. 